\title{
1970 ANNUAL MEETING: RESIDENTS’ COMPETITION
}

\author{
RULES OF COMPETITION
}

1. The objective of the competition shall be to encourage scientific excellence in physicians training in the specialty of anaesthesia in Canada.

2. Candidates must be members or members-elect of the Canadian Anaesthetists' Society at the time of the competition, and occupying the position of Resident, Fellow, or Research Fellow in a Canadian department of anaesthesia. Those completing work beyond the first year of a Master's or Doctoral programme of a Graduate School will be ineligible.

3. The work presented must have been carried out in Canada and completed in the preceding 18 months, prior to obtaining the specialist certificate of the Royal College of Physicians and Surgeons of Canada or of the College of Physicians and Surgeons of Quebec.

4. The Scientific Programme Committee will be responsible for the details of the conduct of the competition and will select the best submissions from those entered, for presentation at the Annual Meeting.

5. The Chairmen of Canadian university departments of anaesthesia (or, in their absence, a previously nominated deputy) will act as judges, scoring each candidate according to a previously agreed system. Three prizes ( $\$ 500, \$ 300, \$ 200)$ will be awarded, at the discretion of the judges, to the best of the eight papers presented at the meeting. The eight papers to be presented will be selected previously by the Scientific Programme Committee, from abstracts (less than 500 words) submitted before March 7, 1970.

6. Entries for the competition should be in the form of abstracts (five copies) and should be submitted, prior to March 7, 1970, to the Chairman, Scientific Programme Committee, Canadian Anaesthetists' Society, 178 St. George Street, Toronto 180. 